\title{
The value of hope: Validation of the perceived hope scale in the Portuguese population
}

\author{
Helena Á. Marujo ${ }^{1,2}$ (D) Maria João Velez ${ }^{1,2} \cdot$ Sónia P. Gonçalves ${ }^{1,2} \cdot$ Luís Miguel Neto $^{1,2} \cdot$ Andreas M. Krafft $^{3}$ • \\ Mafalda Casais ${ }^{4}$
}

Accepted: 12 July 2021

(C) The Author(s), under exclusive licence to Springer Science+Business Media, LLC, part of Springer Nature 2021

\begin{abstract}
Hope is a timeless phenomenon that has witnessed a re-emergence in recent times and has been conceptualized and measured in many different ways. The Perceived Hope Scale (PHS) intends to measure hope in an unbiased way, asking people directly about their experienced levels of hope. This paper presents the validation and psychometric evaluation of the PHS in the Portuguese context. It evaluates the reliability and the factorial structure via exploratory and confirmatory factor analyses, as well as convergent validity and predictive/incremental utility using two samples of 452 adult individuals and 266 university students. Results suggest that the Portuguese version of the PHS exhibits robust psychometric properties: a one-dimensional structure with high internal consistency, as well as convincing convergent validity and predictive power. The PHS was found to relate highly to other psychological dimensions, such as harmony in life, vitality, and flourishing (positively), and negatively with depression and anxiety, adding to their prediction beyond dispositional hope and optimism. Overall, the scale presented here proved to be a useful instrument for assessing perceived hope in the Portuguese context. This study is part of a yearly cross-cultural and crosssectional internet survey entitled Hope Barometer.
\end{abstract}

Keywords Perceived hope $\cdot$ Scale adaptation · Dispositional hope $\cdot$ Harmony in life $\cdot$ Optimism $\cdot$ Vitality $\cdot$ Flourishing Depression · Anxiety

\section{Introduction}

Social sciences and the Humanities have witnessed the reemergence of interest in hope studies since the turn of the millennium. This outburst in hope research was recently explained by Kleist and Jansen (2016) as a phenomenon composed of two congregating processes: a sense of growing volatility, crisis, and uncertainty; and a feeling of scarcity

Helena Á. Marujo

hmarujo@iscsp.ulisboa.pt

1 Instituto Superior de Ciências Sociais e Políticas, Universidade de Lisboa (ISCSP-ULisboa), Campus Universitário do Alto da Ajuda, Rua Almerindo Lessa, 1300-663 Lisbon, Portugal

2 Centro de Administração e Políticas Públicas (CAPP), Lisbon, Portugal

3 Institute of Systemic Management and Public Governance, University of St. Gallen, Gallen, Switzerland

4 CIAUD - Research Centre for Architecture, Urbanism and Design, Lisbon School of Architecture, University of Lisbon, Lisbon, Portugal regarding clear and meaningful leadership and directions for the future - political, economic, ecological, religious, and ideological. Another reason concerns the progressive interest in studying the best in people and focusing on what we want and need to develop as societies. In this sense, positive psychology has helped light the way. Furthermore, the recent interest in the history of emotions also has amplified the relevance of hope (Burke, 2012).

In times when the engagement with the future is so relevant due to circumstances stamped by all kinds of emergencies, conflicts, catastrophes, and their consequences, the role of hope has a special meaning. The relationship of hope with mental health, e.g., anxiety, depression (Arnau et al., 2007), suicide (Beck et al., 1985), substance abuse (Mathis et al., 2009), stress, post-trauma (Long \& Gallagher, 2018), wellbeing (Lee \& Gallagher, 2018), purpose (Cotton Bronk et al., 2009), with academic achievement (Snyder et al., 2002), and with productivity and leadership in the workplace (Adams et al., 2002) has been documented, mostly with consistent results. As a consequence, programs to infuse hope, adequate for different developmental stages of the life course, emerged, making it an intensively researched psychological variable 
from a developmental point of view (Lopez et al., 2009; Marques et al., 2011a, 2011b). Consequently, assessing hope and adapting instruments to different countries is relevant and worthwhile.

The main objective of this study is to validate and study the psychometric qualities of the Perceived Hope Scale (PHS) in the Portuguese context. Portugal is part of the International Hope-Barometer Research Program together with Switzerland, France, Czech Republic, Poland, Spain, South Africa, India, Nigeria, Malta, Italy, Brazil, Colombia, Israel and Australia. The PHS has been validated in German (Krafft et al., 2017), in English (Krafft et al., forthcoming) and in Czech (Slezáčková et al., 2020), and further validation studies are taking place (e.g. Spanish). Therefore, it is important to also validate the instrument in Portuguese (eventually also to be used in Brazil) in order to have a robust measure with the purpose of performing further cross-cultural analyses.

Particularly, Portugal is the westernmost country of mainland Europe and one of the oldest countries on the Iberian Peninsula. It is a modernized and developed industrialized and agricultural country, where tertiary industry is mounting fast, although its history can be located back to about 400,000 years ago (Mingxuan, 2018). According to Hofstede's Cultural Dimensions (Hofstede, 2015; Mingxuan, 2018), Portugal has a high power distance, indicating that the uneven distribution of power is commonly established in organizations. According to Hofstede (2015) Portugal is also a feminine society, where people tend to like what they do, in contrast with craving to be the superlative in their work or attitude. Portuguese culture is uncertaintyavoidant, indicating that Portuguese people feel awkward with indefinite and unclear situations, and are used to following rules. Portuguese culture is described as restrained, since Portuguese people prefer to limit the satisfaction of their desires rather than spend time on leisure or amusement (enjoying aspirations is considered inadequate and even something for which one should apologize), believing that they should focus on working; compared with the indulgent society, Portugal shows relative pessimism (Hofstede, 2015; Mingxuan, 2018). Portugal displays a short-term orientation since its people have great respect for traditions (Mingxuan, 2018). Instead of persevering in achieving long-term results, Portuguese citizens choose to concentrate on short-range aims. Indeed, the Long-Term Orientation factor echoes the degree to which a culture is connected with its past when coping with the challenges that the present and the future pose. The cultures where Short-Term orientation is present tend to preserve longstanding conduct and rituals when confronted with any kind of social change or restructuring (Mingxuan, 2018). Additionally, Portugal is also an exceedingly collectivist culture (Hofstede, 2015, Mingxuan, 2018). Taking into consideration that the Portuguese population has a rather social and communal mentality and is not predominantly performance compelled (Sampaio, 2013), we argue that hope in this culture should be assessed using a much broader measure other than the conventional cognitive, individual and goal-orientated Dispositional Hope Scale (Snyder et al., 1991). Countrywide features can be relevant to explore the interface of hope with the Portuguese cultural context.

As far as we know, there are no studies regarding the general levels of hope in the Portuguese setting, and the ones that research the hope dimension comprise theoretical papers (Querido \& Dixe, 2016), studies with populations experiencing specific physical or psychological diseases (e.g., Charepe et al., 2011; Querido, 2013; Viana, 2010), and the validation of Rick Snyder's Hope scales for adults and children (Lopez et al., 2009; Marques et al., 2011a, 2011b; Marques et al., 2009). Nevertheless, there are some recent indicators of psychological dimensions such as optimism that might be worth mentioning. For instance, on the latest worldwide census conducted by RED C and the WIN Gallup International Group of independent market investigative corporations worldwide (Global Barometer of Hope and Happiness, 2012), which measured optimism for forthcoming economic prosperity, the peak pessimistic nation of those studied was Portugal (Global Barometer of Hope and Happiness, 2012). Additionally, Portugal is in the intermediate level of the classification in what concerns the World Happiness Report, on the 60th position of 156 countries (World Happiness Report, 2020). Regarding peace levels, in 2020 Portugal maintained the third place in the Global Peace Index, only following Iceland and New Zealand, the two top peace nations (Global Peace Index, 2020). Still, in line with Sampaio (2013), we also believe that "only a combined synchronic and diachronic approach of cultural studies - one that is sensitive to national and transnational contexts and intersections" (p. 73) - will allow us to gain a better understanding of the concept of hope.

Looking beyond cultural, sociological and psychological theory and research, hope has had a long history in human existence. Its universal and almost instinctive nature was coined by poets, philosophers, and religious thinkers. Pandora, a mythological Greek figure, unlocked a vessel of evils upon humanity, which spread around the world, and it was precisely hope that remained at the bottom of the jar. A central topic in the Christian faith is uttered in Saint Paul's highlight on faith, hope, and love, namely in St. Paul's first letter to the people of Corinth (1 Corinthians 3). For Saint Thomas Aquinas, hope was one of the theological virtues (Dalferth \& Block, 2016). The English poet Alexander Pope once wrote that "hope springs eternal in the human breast," accentuating its timeless, universal, and comprehensive character (Epistle I of An Essay on Man, a poem published around 17331734). In addition to being present in Western philosophies, the theme is also present in Eastern traditions - such is the example of the Hindu notion of Pratidhi (or Apêksh). Hope has been, through different lenses (religious and secular, big and small, political, cultural, social, psychological and economic), the object 
of artistic, philosophical, scientific and spiritual explorations throughout the centuries (Kleist \& Jansen, 2016).

These numerous expressions suggest that hope has a cultural, religious, social, and political history, and presents complexity. On the one hand, diverse social groups have dissimilar hopes - for redemption, freedom, safety, social progress, or for the afterlife. This is why some authors prefer to discuss it in plural form, rather than as a singular hope (Burke, 2012). On the other hand, the hopes of people also might change with time and space: with lifespan development and with the adjustment of their stories and contexts. For instance, Averill et al. (1990) demonstrated the significance of cultural factors in the diverse perceptions of hope (in terms of targets, sources, and activities of hope) across different populations.

The most popular psychological theory considers hope as "capability to derive pathways to desired goals, and motivate oneself via agency thinking to use those pathways" (Snyder, 2002, p. 249). Therefore, under a cognitive and motivational appraisal, this theory deems hope as an individual disposition for goal-oriented behavior, which is why it is called "dispositional hope" (Snyder, 2002; Snyder et al., 1991). Alternative models of hope also emerged in the literature, defining it as a positive emotion (e.g., Fredrickson, 1998, 2004, 2013; Lazarus, 1999) or conceptualizing it as a character strength, part of the human virtue phenomenon and associated with self-transcendence and development (e.g., Kwon, 2000; Peterson \& Seligman, 2004; Sharma \& Divyanshi, 2016; Wong \& Lim, 2009).

Another approach attempted to address the multifaceted character of hope by integrating cognitive, relational, spiritual, and existential dimensions in its conceptualization. Several measures have been developed to assess hope as a multidimensional phenomenon (Herth, 1991; Scioli et al., 2011). All these instruments have certainly contributed to a better understanding of the complexity of hope. However, what all the before mentioned philosophical, theological, and psychological approaches and research findings tell us, is that hope seems to be a universal and multifaceted psychological experience, which can be studied from many different perspectives; at the same time, no single perspective or theory can explain hope unequivocally and universally for every person alike.

The pitfall of the existing hope theories and measurement instruments is that they impose a certain conceptualization of hope on people, who, in turn, might experience and nurture hope in very different ways, biasing the empirical assessment. This is the case for the Dispositional Hope Scale and its emphasis on cognition and individual capabilities, as well as for alternative scales including spiritual and other dimensions. For example, while religious people ground their hope on religious and spiritual sources, other people revert to their social network or just rely on their own strengths and capabilities. Whereas some highhope people might not be religious or spiritual at all, other people can maintain high levels of hope despite being barely able to contribute personally to the realization of hoped-for outcomes.
The variety of existing hope measures, each based on a different conceptualization of the phenomenon, led to a highly segmented and somewhat confusing research field. Taking into consideration the variety of situations and the many individual modes in which hope can be experienced by different people, there is a need to assess the general perception of hope in a direct, neutral, and unbiased manner. This has been the rationale for the development of the Perceived Hope Scale (PHS) (Krafft et al., 2017) as one central instrument to assess hope across different nations and cultures. Perceived hope is the subjective appraisal of a person's perceived level and the quality of one's own capacity to hope, independently from the possible sources (such as religious, social, or individual) that might have fostered it. The PHS assesses the general level of hopefulness along with the belief in the fulfillment of one's hopes, the dynamic relation between hope and anxiety, the capacity of hope to improve the quality of one's life, as well as the robustness of hope in difficult times.

The PHS is grounded in a philosophic conceptualization that defines hope as the general belief that what is important to the person who hopes (this could be a general desire, a wish, or concrete goals) is considered possible to fulfill, often independently from the (objective) facts, (rational) expectations, and (subjective) likelihood of its realization (Krafft \& Walker, 2018). The PHS was developed in the context of the Hope Barometer international research program, which aims to measure and compare levels and sources of hope across nations and cultures. Previous studies using the original German and English versions of the scale, indicate that hope, as perceived by people, is clearly different from dispositional hope as defined by Snyder et al. (1991) and of optimism as operationalized by Scheier et al. (1994) (Krafft et al., 2017; Krafft \& Walker, 2018).

In this study, we translated the PHS (Krafft et al., 2017) into Portuguese and tested its psychometric properties in terms of reliability and factorial structure, convergent validity, as well as predictive and incremental utility. The study aims to provide the statistical basis for a valid and reliable measure for the assessment of perceived hope in the Portuguese language. This is of value for two reasons: firstly to measure hope among Portuguese people in diverse life circumstances, with different life experiences and individual values and worldviews; secondly, to be able to evaluate the levels of hope and, using other instruments, to investigate the sources and different dimensions of hope in comparison to people in other countries with different cultural backgrounds.

\section{Method}

\section{Samples}

The present research was performed using two samples obtained in the context of the Hope Barometer research program 
in 2018. The advantage of using two different samples is that of replicating the statistical analyses with two groups of people with different backgrounds in terms of age, education, and work activity. Participants in sample I were university students, whereas participants in sample II were full and parttime university employees. The total number of respondents was 718 , of whom $583(81.2 \%)$ were female and 135 (18.8\%) were male.

\section{Sample I}

Sample I comprised 266 university students: 224 of whom were female $(84.2 \%)$ and 42 male $(15.8 \%)$. The average age of respondents was 23 ( $\mathrm{SD}=7.8$, ranging from 18 to 64). Overall, 122 participants $(45.9 \%)$ completed high school, 122 had an undergraduate degree (45.9\%), and 22 participants held a master's or Ph.D. degree (8.2\%).

\section{Sample II}

Sample II comprised 452 participants: 391 (86.3\%) were fulltime employees and 61 (13.7\%) part-time employees, distributed across multiple organizations. Most participants were female $(79.4 \%)$. The average age of participants was 44.6 ( $\mathrm{SD}=11.3$, ranging from 18 to 84 ). The educational attainment was reported as follows: one participant only completed the elementary school $(0.2 \%)$, two participants completed middle school $(0.4 \%), 57$ completed high school $(12.8 \%)$, 226 had an undergraduate degree $(49.9 \%)$, and 166 participants held a master's or Ph.D. degree (36.6\%).

During sampling, one participant who was under 18 responded, but her/his data were not used because of minorage status.

\section{Procedure}

The initial phase consisted of three steps in line with the conventional method of back translation (Brislin, 1970). Firstly, the measures were translated from English to Portuguese using the parallel back-translation procedure. Back translation involves translating the measures from English to Portuguese by an expert, and secondly translating them back to the original language by another expert, without the use of the original measures (Brislin, 1970). This method provides an initial adequacy assessment of the translated measures. In the third step, we proceeded to pre-test the Portuguese version of the questionnaire on 20 participants (who were not included in final the sample). The pre-test did not reveal any major issues concerning our surveys. Following the recommendations of Van de Vijver and Hambleton (1996) we tried to produce a Portuguese version that, preserving the ideas contained in the original scale, was adequate to the Portuguese context and, simultaneously, as close as possible to the original version.
Afterwards, data was collected through an open online survey and was conducted within the social networks of the authors, during the 3rd quarter of 2018. Employees and students from the higher education institution received an email sent through the institutional mailing list. Additionally, an invitation to answer the survey was published on the institutional website. By accessing the online questionnaire, participants were informed about its aim and the voluntary nature of their participation, as well being assured of the confidentiality of their responses. In addition to the full version of the scales, the questionnaire also included sociodemographic questions to characterize both samples (gender, age, educational level, and employment relationship). The present study was conducted in compliance with the principles of the 1964 Declaration of Helsinki and its later addenda.

\section{Measures}

Perceived Hope Scale The PHS contains six items to measure individual judgment about one's experience and levels of hope (Krafft et al., 2017). An example of an item is "I am hopeful with regard to my life." The response to these items was made on a 6-point scale (ranging from $0=$ strongly disagree to $5=$ strongly agree). None of the items is reverse coded. In the validation article of the original scale Cronbach alpha values of .87 and .89 were reported.

Dispositional Hope Scale This scale contains eight items in total: the four-item Agency subscale and the four-item Pathways subscale (Snyder et al., 1991). Examples of items include "I energetically pursue my goals" and "There are lots of ways around any problem," respectively. Items are scored on a 6-point Likert scale (ranging from $0=$ strongly disagree to $5=$ strongly agree). This scale was validated with Portuguese students by Marques et al. (2014) with a Cronbach alpha value of .86 .

Revised Life Orientation Test This six-item scale was used to assess individual differences in optimism and pessimism (Scheier et al., 1994) with a 6-point Likert-type scale (ranging from $1=$ strongly disagree to $6=$ strongly agree). Sample items include "In uncertain times, I usually expect the best" and "If something can go wrong to me, it will." This scale was validated with the Portuguese population by Laranjeira (2008) with a Cronbach alpha value of .71.

Subjective Vitality Scale This is a seven-item scale designed to assess individuals' feelings of aliveness and the positive energy that arises from acting in self-actualizing ways (Ryan \& Frederick, 1997). Items include "I feel alive and vital" and "I have energy and spirit," and are rated on a 7-point Likert scale ( $1=$ strongly disagree, $7=$ strongly agree). The Portuguese 
Table 1 Means, standard deviations, and internal consistency reliability coefficients for Perceived Hope Scale across sample I and sample II

\begin{tabular}{lllllll}
\hline Descriptive statistics & $N$ & Minimum & Maximum & $\alpha$ & Mean & SD \\
\hline Sample I & 266 & .50 & 5 & .87 & 3.17 & .96 \\
Sample II & 452 & .00 & 5 & .89 & 3.88 & .78 \\
\hline
\end{tabular}

version was validated with Portuguese elderly by Couto et al. (2017) with a Cronbach alpha value of .80 .

Flourishing Scale This is an eight-item scale of positive human functioning (Diener et al., 2010). Answers are made on a 7point Likert scale ( $1=$ strongly disagree, $7=$ strongly agree $)$. An example item is "I lead a purposeful and meaningful life." The Portuguese version was validated by Silva and Caetano (2013) using a sample of employees and a sample of university students, with Cronbach alpha values of .78 and .83, respectively.

Depression and Anxiety We used the PHQ-4 (The Patient Health Questionnaire-4; Kroenke et al., 2009; Löwe et al., 2010) to assess symptoms of depression and anxiety, assessed through a 4-point Likert scale ( $1=$ not at all, $4=$ nearly every day). Example items include "Feeling nervous, anxious, or on edge" and "Feeling down, depressed, or hopeless."

Harmony in Life Scale This scale is a five-item measure of psychological balance and flexibility in life (Kjell et al., 2016). An example of an item is "My lifestyle allows me to be in harmony." Responses were made on a 7-point scale, ranging from $1=$ strongly agree to $7=$ strongly disagree.

\section{Data Analysis}

The validation of the Portuguese version of the PHS was done in four steps, using SPSS and AMOS 25 software: (1) Exploratory factor analysis; (2) Confirmatory factor analysis; (3) Convergent validity; and (4) Predictive and incremental utility. The analyses in Steps 1 to 3 were performed with samples I and II separately, while in Step 4 we merged the two groups into one total sample.

Table 2 Goodness of fit statistics for tests of factorial validity of the Perceived Hope Scale

\begin{tabular}{lllllllllll}
\hline \multicolumn{1}{l}{$X^{2}$} & df $p$ & CFI & GFI & AGFI & RMSEA & SRMR & NFI \\
\hline Sample I & 35.078 & 9 & .000 & .97 & .96 & .91 & .10 & .04 & .96 \\
Sample II & 67.807 & 9 & .000 & .96 & .95 & .88 & .12 & .04 & .96 \\
\hline
\end{tabular}

CFI comparative fit index, GFI goodness of fit index, $A G F I$ adjusted goodness of fit index, RMSEA root mean square error of approximation, $S R M R$ standardized root mean square, NFI normed fit index

\section{Results}

\section{Preliminary Results}

Before proceeding with the core statistical analyses, we verified the normality of the data and identified multivariate outliers using Mahalanobis distance (Mahalanobis, 1936) on the two samples. We detected and deleted four outliers in sample I and twelve outliers in sample II. Furthermore, the normality of the data was investigated by calculating skewness and kurtosis and comparing them with the "rule of thumb values" of \pm 2.58 (Hair et al., 2010). Skewness values ranged from -.99 to -.05 (sample I) and from -1.51 to -.69 (sample II), thus being inside the threshold which indicated that respondents answered these questions quite similarly. Kurtosis values ranged from .66 to 1.94 (sample I) and from 1.02 to 1.11 (sample II), again falling within the recommendation range.

Results from Bartlett Sphericity tests - sample I: $\chi 2$ (15) = 842.833; $p<.000$ and sample II: $\chi 2(15)=1535.893 ; p<.000$ - and results from the Kaiser-Meyer-Olkin measure of sampling adequacy - sample I: $\mathrm{KMO}=.870$ and sample II: $\mathrm{KMO}=.882-$ ensure data adequacy. Regarding the remaining scales, skewness and kurtosis values are also inside the suggested thresholds in all cases. Results from Bartlett Sphericity tests and from the Kaiser-Meyer-Olkin measure of sampling adequacy ensure data adequacy of all scales. Furthermore, in both samples we obtained Cronbach alpha values above .70 for all scales and subscales.

The mean values of the items that comprise the PHS varied from 2.53 to 3.60 (sample I); and 3.56 to 4.43 (sample II). As Table 1 indicates, participants in sample II (adults in the work process) presented a higher value of perceived hope $(\mathrm{M}=$ 3.88; $\mathrm{SD}=.78$ ) (see Table 1 for descriptive statistics and internal consistency coefficients).

\section{Step1: Exploratory Factor Analysis}

Results obtained in the original study (Krafft et al., 2017) indicate a one-dimensional model for the PHS. The factorial analysis of the Portuguese samples using the principal axis method revealed a single factor in both samples, with eigenvalues higher than 1 (sample I: $\lambda 1=3962$; sample II: $\lambda 1=$

Table 3 Goodness of fit statistics for tests of factorial validity of the Perceived Hope Scale correlating the residuals of items 1 and 6

\begin{tabular}{lllllllllll}
\hline & $X^{2}$ & df & $p$ & CFI & GFI & AGFI & RMSEA & SRMR & NFI \\
\hline Sample I & 14.022 & 8 & .081 & .99 & .98 & .96 & .052 & .019 & .98 \\
Sample II & 11.839 & 8 & .159 & .99 & .99 & .98 & .033 & .016 & .99 \\
\hline
\end{tabular}

$C F I$ comparative fit index, $G F I$ goodness of fit index, $A G F I$ adjusted goodness of fit index, RMSEA root mean square error of approximation, $S R M R$ standardized root mean square, NFI normed fit index 
Table 4 Descriptive statistics and correlations between the Perceived Hope Scale and dispositional hope (agency and pathways), optimism, subjective vitality, flourishing, harmony in life and depression/anxiety

\begin{tabular}{|c|c|c|c|c|c|c|c|}
\hline & DHS - Agency & DHS - Pathways & Optimism (LOT-R) & Vitality & Flourishing & HiL & DA \\
\hline Sample I & $\begin{array}{l}M=3.53 \\
S D=.78\end{array}$ & $\begin{array}{l}M=3.73 \\
S D=.79\end{array}$ & $\begin{array}{l}\mathrm{M}=3.95 \\
\mathrm{SD}=.94\end{array}$ & $\begin{array}{l}\mathrm{M}=4.72 \\
\mathrm{SD}=.1 .17\end{array}$ & $\begin{array}{l}M=.5 .72 \\
S D=.78\end{array}$ & $\begin{array}{l}\mathrm{M}=5.07 \\
\mathrm{SD}=.1 .12\end{array}$ & $\begin{array}{l}M=2.16 \\
S D=.72\end{array}$ \\
\hline Sample II & $\mathrm{M}=3.81 \mathrm{SD}=.67$ & $\begin{array}{l}\mathrm{M}=4.00 \\
\mathrm{SD}=.64\end{array}$ & $\mathrm{M}=4.45 \mathrm{SD}=.79$ & $\mathrm{M}=.5 .15 \mathrm{SD}=.1,03$ & $M=5.99 \mathrm{SD}=.68$ & $\mathrm{M}=5.53 \mathrm{SD}=1.05$ & $\mathrm{M}=1.70 \mathrm{SD}=.58$ \\
\hline Sample I & & & & & & & \\
\hline $\begin{array}{l}\text { PHS } \\
\text { Sample II }\end{array}$ & $.58 * *$ & $.58 * *$ & $.54 * *$ & $.59 * *$ & $.55^{* *}$ & $.54 * *$ & $-.46^{* *}$ \\
\hline PHS & $.60 * *$ & $.59 * *$ & $.59 * *$ & $.62 * *$ & $.68^{* *}$ & $.62 * *$ & $-.50 * *$ \\
\hline
\end{tabular}

DHS Dispositional Hope Scale, LOT-R Life Orientation Test Revised, HiL Harmony in Life, DA Depression /Anxiety, PHS Perceived Hope Scale $* * p<.01$

3805). Thus, this factor explains $66.03 \%$ (sample I) and $63.42 \%$ (sample II) of the total variance. In addition, there were no other eigenvalues higher than 1 , with factorial loadings varying between .73 and .88 (sample I), and between .63 and .86 (sample II). Therefore, we can conclude that only one factor composes the PHS, with Cronbach alpha values of .88 (sample I) and 89 (sample II).

\section{Step 2: Confirmatory Factor Analysis}

In order to examine the goodness of fit indices, we conducted two distinct confirmatory factor analyses, one for each sample independently (see Table 2 for the goodness of fit statistics). All standardized factor loadings were statistically significant at $p<.01$. They ranged from .62 to .87 in sample I, and from .62 to .89 in sample II. Much better goodness of fit indices was achieved when correlating the residuals of item 1 and item 6 (see Table 3). This makes theoretical sense, since both items address specifically positive and negative aspects, i.e., hope and anxiety (item 1) and hope in adverse situations (item 6). The two samples presented similar fit indices, clearly indicating the solution of a single factor and, consequently, the onedimensional structure of the scale.

\section{Step 3: Convergent Validity}

To assess convergent validity, we correlated the PHS (Krafft et al., 2017) with the two subscales of dispositional hope, agency and pathways (Snyder et al., 1991), optimism (Scheier et al., 1994), subjective vitality (Ryan \& Frederick, 1997), flourishing (Diener et al., 2010), harmony in life (Kjell et al., 2016), and depression/anxiety (Kroenke et al., 2009; Löwe et al., 2010). Table 4 shows that the correlation coefficient between perceived hope and depression/anxiety ranges from -.46 (sample I) to - .50 (sample II), while the correlation coefficients with the remaining measures vary from .54 to .64 (sample I), and from .59 to .68 (sample II). The PHS correlates significantly with all variables, evidencing the construct validity of the scale.

\section{Step 4: Predictive and Incremental Utility}

The predictive and incremental utility of the PHS using the total sample is presented in Table 5.

We performed four hierarchical regression analyses with depression/anxiety, subjective vitality, flourishing, and harmony in life defined as dependent variables. In each analysis,
Table 5 Hierarchical regression analyses

\begin{tabular}{|c|c|c|c|c|c|c|c|c|c|}
\hline $\begin{array}{l}\text { Step/ } \\
\text { Model }\end{array}$ & Predictors & $\begin{array}{l}\text { Adj. } \\
\mathrm{R}^{2}\end{array}$ & $\Delta \mathrm{R}^{2}$ & $\Delta \mathrm{F}$ & $\begin{array}{l}\beta \text { Model } \\
3\end{array}$ & $\begin{array}{l}\text { Adj. } \\
\mathrm{R}^{2}\end{array}$ & $\Delta \mathrm{R}^{2}$ & $\Delta \mathrm{F}$ & $\begin{array}{l}\beta \text { Model } \\
3\end{array}$ \\
\hline & & \multicolumn{4}{|c|}{ Depression / Anxiety } & \multicolumn{4}{|c|}{ Subjective Vitality } \\
\hline 1 & LOT-R & $.253 * *$ & $.253^{* *}$ & 240.43 & $-.218 * *$ & $.273 * *$ & $.273 * *$ & 267.44 & $.128 * *$ \\
\hline 2 & DHS & $.315 * *$ & $.061^{* *}$ & 63.33 & $-.178 * *$ & $.419^{* *}$ & $.146^{* *}$ & 179.85 & $.330 * *$ \\
\hline \multirow[t]{2}{*}{3} & PHS & $.350 * *$ & $.035^{* *}$ & 38.00 & $-.280 * *$ & $.462 * *$ & $.043^{* *}$ & 57.58 & $.313 * *$ \\
\hline & & \multicolumn{4}{|c|}{ Flourishing } & \multicolumn{4}{|c|}{ Harmony in Life } \\
\hline 1 & LOT-R & $.336 * *$ & $.336^{* *}$ & 359.56 & $.191 * *$ & $.264 * *$ & $.264 * *$ & 255.61 & $.141 * *$ \\
\hline 2 & DHS & $.497 * *$ & $.161^{* *}$ & 229.47 & $.378 * *$ & $.388 * *$ & $.124 * *$ & 144.54 & $.293 * *$ \\
\hline 3 & PHS & $.527 * *$ & $.030^{* *}$ & 45.30 & $.260 * *$ & $.431 * *$ & $.043 * *$ & 54.32 & $.313 * *$ \\
\hline
\end{tabular}

LOT-R Life Orientation Test revised, DHS Dispositional Hope Scale, PHS Perceived Hope Scale; ** $p<.001$ 
we entered as predictors the LOT-R in Step 1, the DHS in Step 2 and the PHS in Step 3. The results reported in Table 5 show that all models are significant (model $1=$ LOT-R; model $2=$ LOT $-\mathrm{R}+\mathrm{DHS} ;$ model $3=\mathrm{LOT}-\mathrm{R}+\mathrm{DHS}+\mathrm{PHS})$. In all cases, the PHS is a significant and strong predictor of the dependent variables. The results indicate that the PHS contributes uniquely to the prediction of depression/anxiety $(+3.5 \%)$, subjective vitality $(+4.3 \%)$, flourishing $(+3 \%)$, and harmony in life $(+4.3 \%)$ not explained by the LOT-R and the DHS. Moreover, the PHS is the strongest predictor of harmony in life $(\beta=.313)$ and of depression/anxiety $(\beta=-.280)$.

\section{Discussion}

This paper presented the validation of the Portuguese version of PHS, as well as the metric qualities of the instrument. In parallel with the original version (Krafft et al., 2017), the Portuguese version of the PHS was found to have high levels of fidelity, which attest to the high internal consistency of the scale, as well as convincing convergent validity. Regarding factor analysis, the instrument presents a one-dimensional structure, as postulated by the original scale's authors. Furthermore, the PHS seems to be a good and distinct predictor of several measures of health and wellbeing. Our findings not only attest the good psychometric properties of the PHS, but beyond that support the fundamental idea that it is worthwhile to have an instrument to measure hope as perceived by people. It seems as if hope as perceived by people is something different than positive expectations in terms of optimism and individual goal-oriented agency and pathways cognitions as suggested by the authors of the scale. Thus, our study adds to the evaluation of the PHS, supporting its value as a robust instrument to measure hope in different countries in a neutral form, independently from predefined concepts and definitions held by researchers.

One limitation of the current study is the high level of education of participants, as well as the preponderance of females over males in both samples. Thus, broadening sampling to include a wider range of education levels is desirable. Furthermore, future research should extend the proportion of male and female respondents so that possible gender differences could be explored. Data collection was done with an online tool, potentially excluding older segments of the population or people without internet access. The instrument will benefit from extending its validation to more differentiated groups, to generalize its use in the Portuguese population.

It is expected that in the future the scale be integrated in Portuguese psychological research, continuing its use and deepening the study of perceived hope, which is a relevant dimension of our individual and collective lives.

\section{Appendix}

\section{Perceived Hope Scale Portuguese version}

Até que ponto as informações abaixo se aplicam a si?

1. Na minha vida, a esperança tem mais peso do que a ansiedade

2. As minhas esperanças normalmente realizam-se

3. Sinto-me esperançoso/a

4. A esperança melhora a minha qualidade de vida

5. Sinto-me esperançado/a em relação à minha vida

6. Mantenho a esperança mesmo em tempos difíceis

$0=$ discordo fortemente $; 1=$ discordo $; 2=$ discordo ligeiramente; $3=$ concordo ligeiramente; $4=$ concordo; $5=$ concordo fortemente or $0=$ discordo totalmente; $1=$ discordo; $2=$ discordo parcialmente; $3=$ concordo parcialmente; $4=$ concordo $; 5=$ concordo totalmente

Data Availability The data that support the findings of this study are available from the corresponding author upon reasonable request.

\section{Declarations}

Conflict of Interest The authors declare that the research was conducted in the absence of any commercial or financial relationships that could be construed as a potential conflict of interest.

Informed Consent Informed consent was obtained from all individual participants included in the study.

Research Involving Human Participants and/or Animals (1964 Declaration of Helsinki) Ethical review and approval was not required for the study on human participants in accordance with the local legislation and institutional requirements. The participants provided their written informed consent to participate in this study.

We are enclosing herewith a paper entitled "The value of hope: Validation of the Perceived Hope Scale in the Portuguese population" for publication in the Journal Applied Research in Quality of Life. This manuscript has not been published, accepted for publication or under editorial review for publication in another journal.

The submitted paper is a research article that describes the validation of an assessment measure of hope in the Portuguese context, in a neutral and unbiased form - the Perceived Hope Scale (PHS). All the scales involved had the full permission of the authors.

The manuscript in full has not been submitted or published anywhere an is original.

The manuscript will not be submitted elsewhere until the editorial process is completed.

No part of the manuscript contains previously published content, so all the authors state the permission to reproduce the material.

All the authors involved made substantial contributions to the conception of the work, and the acquisition, analysis, and interpretation of data.

Authors also state that written informed consent was obtained from the participants of the study while answering the questionnaire.

All the authors mentioned in the manuscript have agreed for authorship, read and approved the manuscript, and given consent for submission and subsequent publication of the manuscript.

The order of authorship was agreed by all named authors prior to submission. 
We thereby inform that there are no conflict of interests, the study was anonymous and that all the ethical standards related to this type of study where followed, namely respect third parties rights such as copyright and/ or moral rights.

\section{References}

Adams, V. H., Snyder, C. R., Rand, K. L., King, E. A., Sigmon, D. R., \& Pulvers, K. M. (2002). Hope in the workplace. In C. L. Jurkiewicz \& R. A. Giacalone (Eds.), Handbook of workplace spirituality and organizational performance (pp. 367-377). M.E. Sharpe.

Arnau, R. C., Rosen, D. H., Finch, J. F., Rhudy, J. L., \& Fortunato, V. J. (2007). Longitudinal effects of hope on depression and anxiety: A latent variable analysis. Journal of Personality, 75(1), 43-64. https://doi.org/10.1111/j.1467-6494.2006.00432.x.

Averill, J. R., Catlin, G., \& Chon, K. K. (1990). Rules of hope. Springer.

Beck, A. T., Steer, R. A., Kovacs, M., \& Garrison, B. (1985). Hopelessness and eventual suicide: A 10-year prospective study of patients hospitalized with suicidal ideation. American Journal of Psychiatry, 142, 559-563. https://doi.org/10.1176/ajp.142.5.559.

Brislin, R. W. (1970). Back-translation for cross-cultural research. Journal of Cross-Cultural Psychology, 1(3), 185-216. https://doi. org/10.1177/135910457000100301.

Burke, P. (2012). Does hope have a history? Estudos Avançados, 26(75), 207-218. https://doi.org/10.1590/S0103-40142012000200014.

Charepe, Z. B., Figueiredo, M., Vieira, M., \& Neto, L. (2011). (Re)discovering hope in families of children with chronic disease through genogram and ecomap [Portuguese]. Texto \& Contexto Enfermagem, 20(2), 349-358. https://doi.org/10.1590/S010407072011000200018.

Cotton Bronk, K., Hill, P. L., Lapsley, D. K., Talib, T. L., \& Finch, H. (2009). Purpose, hope, and life satisfaction in three age groups. The Journal of Positive Psychology, 4(6), 500-510. https://doi.org/10. 1080/17439760903271439.

Couto, N., Antunes, R., Monteiro, D., Moutão, J., Marinho, D., \& Cid, L. (2017). Validation of the subjective vitality scale and study of the vitality of elderly people according to their physical activity. Revista Brasileira de Cineantropometria \& Desempenho Humano, 19(3), 261-269. https://doi.org/10.5007/1980-0037.2017v19n3p261.

Dalferth, I.U., \& Block, M.A. (2016). Hope. Claremont Studies in the Philosophy of Religion, Conference 2013. Tübingen, Germany: Mohr Siebeck. ISBN-13 : 978-3161537141.

Diener, E., Wirtz, D., Tov, W., Kim-Prieto, C., Choi, D.-w., Oishi, S., \& Biswas-Diener, R. (2010). New well-being measures: Short scales to assess flourishing and positive and negative feelings. Social Indicators Research, 97(2), 143-156. https://doi.org/10.1007/ s11205-009-9493-y.

Fredrickson, B. L. (1998). What good are positive emotions? Review of General Psychology, 2, 300-319. https://doi.org/10.1037/10892680.2.3.300

Fredrickson, B. L. (2004). Gratitude, like other positive emotions, broadens and builds. In R. A. Emmons \& M. E. McCullough (Eds.), Series in affective science. The psychology of gratitude (pp. 145-166). Oxford University Press.

Fredrickson, B. L. (2013). Chapter one - positive emotions broaden and build. In P. Devine \& A. Plant (Eds.), Advances in experimental social psychology, volume 47 (pp. 1-53). Academic Press.

Hair, J. F., Black, W. C., Babin, B. J., \& Anderson, R. E. (2010). Multivariate data analysis: A global perspective. Pearson.

Helliwell, J. F., Layard, R., Sachs, J. D., \& De Neve, J. (Eds.). (2020). World Happiness Report 2020. New York: Sustainable Development Solutions Network.

Herth, K. (1991). Development and refinement of an instrument to measure hope. Research and Theory for Nursing Practice, 5(1), 39-51.
Hofstede, G. (2015). The Hofstede Centre: Strategy, Culture, Change. http://geert-hofstede.com/countries.html

Institute for Economics \& Peace (2020). Global Peace Index 2020: Measuring peace on a complex World. https://www. visionofhumanity.org/wp-content/uploads/2020/10/GPI 2020 web.pdf

Kjell, O. N. E., Daukantaite,, D., Hefferon, K., \& Sikström, S. (2016). The harmony in life scale compliments the satisfaction with life scale: Expanding the conceptualization of the cognitive component of subjective well-being. Social Indicators Research, 126(2), 893-919. https://doi.org/10.1007/s11205-015-0903-z.

Kleist, N., \& Jansen, S. (2016). Introduction: Hope over time - Crisis, immobility and future-making. History and Anthropology, 27(4), 373-392. https://doi.org/10.1080/02757206.2016.1207636.

Krafft, A. M., \& Walker, A. M. (2018). Exploring the concept and experience of Hope: Empirical findings and the virtuous circle of Hope. In A. M. Krafft, P. Perrig-Chiello, \& A. M. Walker (Eds.), Hope for a good life: Results of the Hope Barometer Research Program (pp. 21-60). Springer.

Krafft, A. M., Martin-Krumm, C., \& Fenouillet, F. (2017). Adaptation, further elaboration, and validation of a scale to measure hope as perceived by people: Discriminant value and predictive utility Visà-Vis dispositional hope. Assessment, 24, 1-16. https://doi.org/10. 1177/1073191117700724.

Krafft, A., Guse, T. \& Maare D. (forthcoming). Distinguishing perceived Hope and dispositional optimism: Theoretical foundations and empirical findings beyond future expectancies and cognition. Springer.

Kroenke, K., Spitzer, R. L., Williams, J. B., \& Löwe, B. (2009). An ultrabrief screening scale for anxiety and depression: The PHQ-4. Psychosomatics, 50(6), 613-621. https://doi.org/10.1016/S00333182(09)70864-3.

Kwon, P. (2000). Hope and dysphoria: The moderating role of defense mechanisms. Journal of Personality, 68(2), 199-223. https://doi. org/10.1111/1467-6494.00095.

Laranjeira, C. A. (2008). Tradução e validação portuguesa do revised life orientation test (LOT-R). Universitas Psychologica, 7(2), 476-476. http://www.scielo.org.co/pdf/rups/v7n2/v7n2a13.pdf

Lazarus, R. S. (1999). Hope: An emotion and a vital coping resource against despair. Social Research, 66(2), 653-678.

Lee, J. Y., \& Gallagher, M. W. (2018). Hope and well-being. In M. W. Gallagher \& S. J. Lopez (Eds.), The Oxford handbook of Hope (pp. 287-298). Oxford University Press.

Long, L. J., \& Gallagher, M. W. (2018). Hope and posttraumatic stress disorder. In M. W. Gallagher \& S. J. Lopez (Eds.), The Oxford handbook of hope (pp. 233-242). Oxford University Press.

Lopez, S.J., Rose, S., Robinson, C., Marques, S.C., \& Pais-Ribeiro, J. (2009). Measuring and promoting hope in schoolchildren. Handbook of positive psychology in the schools (pp. 37-51). Routledge.

Löwe, B., Wahl, I., Rose, M., Spitzer, C., Glaesmer, H., Wingenfeld, K., Schneider, A., \& Brähler, E. (2010). A 4-item measure of depression and anxiety: Validation and standardization of the patient health Questionnaire-4 (PHQ-4) in the general population. Journal of Affective Disorders, 122(1-2), 86-95. https://doi.org/10.1016/j.jad. 2009.06.019.

Mahalanobis, P. C. (1936 [2018]). On the generalised distance in statistics. Sankhya A, 80,1-7. https://doi.org/10.1007/s13171-01900164-5.

Marques, S. C., Pais-Ribeiro, J. L., \& Lopez, S. J. (2011a). Of a Portuguese version of the children's hope scale. School Psychology International, 30(5), 538-551. https://doi.org/10.1177/ 0143034309107069.

Marques, S. C., Lopez, S. J., \& Pais-Ribeiro, J. L. (2011b). "Building hope for the future:" A program to foster strengths in middle-school students. The Journal of Happiness Studies, 12(1), 139-152. https:// doi.org/10.1007/s10902-009-9180-3. 
Marques, S. C., Lopez, S. J., Fontaine, A. M., Coimbra, S., \& Mitchell, J. (2014). Validation of a Portuguese version of the Snyder Hope Scale in a sample of high school students. Journal of Psychoeducational Assessment, 32(8), 781-786. https://doi.org/10.1177/ 0734282914540865.

Marques, S. C., Pais-Ribeiro, J., \& Lopez, S. J. (2009). Validation of a Portuguese Version of the Children's Hope Scale. School Psychology International, 30(5), 538-551.

Mathis, G. M., Ferrari, J. R., Groh, D. R., \& Jason, L. A. (2009). Hope and substance abuse recovery: The impact of agency and pathways within an abstinent communal-living setting. Journal of Groups in Addiction \& Recovery, 4(1-2), 42-50. https://doi.org/10.1080/ 15560350802712389.

Mingxuan, D. (2018). Portuguese cultural standards from the chinese perspective.e [Unpublished master dissertation]. ISCTE Business School.

Peterson, C., \& Seligman, M.E.P. (2004). Character strengths and virtues: A handbook and classification. American Psychological Association; Oxford University Press.

Querido, A. (2013). A promoção da esperança em fim de vida: avaliação da efetividade de um programa de intervenção em pessoas com doença crónica avançada e progressiva. [Unpublished doctoral dissertation]. Universidade Católica Portuguesa.

Querido, A., \& Dixe, M. A. (2016). A esperança na saúde mental: Uma revisão integrativa da literatura. Revista Portuguesa de Enfermagem de Saúde Mental (3), 95-101. doi: 10.19131/rpesm.0124.

RED C Research (2012). RED C Global Barometer of Hope and Happiness. https://www.redcresearch.com/global-barometer-ofhope-happiness/

Ryan, R., \& Frederick, C. (1997). On energy, personality, and health: Subjective vitality as a dynamic reflection of well-being. Journal of Personality, 65(3), 529-565. https://doi.org/10.1111/j.14676494.1997.tb00326.x.

Sampaio, S. (2013). Portuguese cultural studies/cultural studies in Portugal: Some thoughts on the making and remaking of a field. Culture Unbound Journal of Current Cultural Research, 5(1), 7388.

Scheier, M. F., Carver, C. S., \& Bridges, M. W. (1994). Distinguishing optimism from neuroticism (and trait anxiety, self-mastery, and selfesteem): Reevaluation of the Life Orientation Test. Journal of Personality and Social Psychology, 67(6), 1063-1078. https://doi. org/10.1037/0022-3514.67.6.1063.

Scioli, A., Ricci, M., Nyugen, T., \& Scioli, E. R. (2011). Hope: Its nature and measurement. Psychology of Religion and Spirituality, 3(2), 78 97. https://doi.org/10.1037/a0020903.
Sharma, M., \& Divyanshi, G. (2016). Personal growth as a correlate of gratitude, hope and curiosity among college students. Indian. Journal of Positive Psychology, 7(2), 201-205. https://doi.org/10. 15614/ijpp\%2F2016\%2Fv7i2\%2F122100.

Silva, A. J., \& Caetano, A. (2013). Validation of the flourishing scale and scale of positive and negative experience in Portugal. Social Indicators Research, 110(2), 469-478. https://doi.org/10.1007/ s11205-011-9938-y.

Slezáčková, A., Prošek, T., Malatincová, T., \& Krafft, A. M. (2020). Psychometrické vlastnosti české verze škály prožívané naděje: faktorová struktura a vnitřní konzistence [Psychometric characteristics of the Czech version of The Perceived Hope Scale: factor structure and internal consistency]. Československá psychologie / Czechoslovak Psychology, 64(3), 288-305 http://www.medvik.cz/ link/bmc20012388.

Snyder, C. R. (2002). Hope theory: Rainbows in the mind. Psychological Inquiry, 13(4), 249-275. https://doi.org/10.1207/ S15327965PLI1304_01.

Snyder, C. R., Harris, C., Anderson, J. R., Holleran, S. A., Irving, L. M., Sigmon, S. T., Yoshinobu, L., Gibb, J., Langelle, C., \& Harney, P. (1991). The will and the ways: Development and validation of an individual-differences measure of hope. Journal of Personality and Social Psychology, 60(4), 570-585. https://doi.org/10.1037/00223514.60.4.570.

Snyder, C. R., Shorey, H. S., Cheavens, J., Pulvers, K. M., Adams III, V. H., \& Wiklund, C. (2002). Hope and academic success in college. Journal of Educational Psychology, 94(4), 820-826. https://doi.org/ 10.1037/0022-0663.94.4.820.

Van de Vijver, F., \& Hambleton, R. K. (1996). Translating tests. Some practical guidelines. European Psychologist, 1(2), 89-99. https:// doi.org/10.1027/1016-9040.1.2.89.

Viana, A. P. M. (2010). A avaliação da esperança em cuidados paliativos: Validação Transcultural do Herth Hope Index. [Unpublished master dissertation]. Faculdade de Medicina, Universidade de Lisboa.

Wong, S. S., \& Lim, T. (2009). Hope versus optimism in Singaporean adolescent: Contribution to depression and life satisfaction. Personality and Individual Difference, 46(5-6), 648-652.

Publisher's Note Springer Nature remains neutral with regard to jurisdictional claims in published maps and institutional affiliations. 